\title{
Pathways to educational engagement: an exploratory study of outcomes from an Australian school-based youth mentoring program
}

\author{
Ariella Meltzer, Abigail Powell \& Isabella Saunders
}

\begin{abstract}
School-based mentoring (SBM) programs are seen as a way of preventing the disengagement of young people from education. However, existing research points to a complex relationship between SBM programs and improved engagement outcomes. There is therefore a need for greater understanding of the pathways through which SBM leads to outcomes for young people. This paper addresses this complexity, examining the nuanced ways in which SBM may lead to positive outcomes for young people. Drawing on the qualitative perspectives of 15 young people engaged in an Australian SBM program, the findings point to two types of pathways to outcomes. First, direct pathways go to the heart of young people's engagement, by prioritizing educational performance and achievement as the focus of the mentoring relationship. Second, holistic pathways see mentors seeking to influence young people's broader thinking about the value of education, their wellbeing and their communication skills, to in turn address issues that may otherwise present barriers to young people's engagement. The paper discusses the policy implications of the findings. It highlights the importance of acknowledging and measuring incremental steps to improved educational engagement, in a context of young people experiencing non-linear and complex pathways to engagement outcomes.
\end{abstract}

KEYWORDS: Young people, school-based mentoring, educational engagement

\section{Introduction}

Internationally, approximately $11-14 \%$ of young people aged $15-29$ are not in education, employment or training (Powell 2017). Such disengagement presents risks for young people's physical and mental health and their level of social connectedness (Reeve et al. 2016), as well as for long-term disengagement and un- or under-employment in later adulthood (Coles et al. 2010; Shildrick et al. 2012). High rates of disengagement among young people also have significant implications for national economies, where countries with an ageing population increasingly rely on a younger workforce and cannot afford to have young people disengaged from work (FYA 2016). In this context, governments and other actors are increasingly concerned with approaches that can enable pathways out of disengagement for young people (e.g. Jacob 2008; García-Carrión, MolinaLuque, and Roldán 2018). Here, pathways refer to interventions that enable a sequence of actions and resulting changes that lead to progress towards a desired outcome - in this case, improved engagement among young people.

One popular intervention has been mentoring young people perceived to be at-risk of disengaging from education. Youth mentoring involves the development of a relationship in which ongoing guidance, instruction and encouragement is offered by an adult that contributes to the personal development of a young person (Rhodes 1994; Rhodes, Grossman, and Roffman 2002). Sometimes the relationship develops naturally (informal mentoring), while at other times the relationship is purposefully cultivated through social policy programs, by assigning an adult to a young person 
(formal mentoring) (Rhodes et al. 2002). In both approaches, the mentoring relationship itself is the vehicle for support and personal development (Henry 2006). The intention is that, through the relationship, there is ongoing contact, communication and trust between the adult and young person that cultivates resources for the young person's personal development, which may aid positive outcomes in relation to dis/engagement. These resources may relate to how young people feel about themselves, their capacity for direction-setting and decision-making, their skills and qualifications, and how they navigate networks that can assist them to engage both socially (e.g. with friends and family) and economically (e.g. with school and/or work) (Pawson 2004). While mentors may share some qualities with others in young people's lives, such as teachers, they are distinct in that the primary purpose of the mentoring relationship is personal development, rather than, for example, education in the sense of teaching a school curriculum.

Historically, mentoring has most commonly been offered in community-based programs, although other forms of delivery are becoming widespread. School-based mentoring (SBM) - in which mentoring is delivered in a series of one-on-one conversations in a supervised school setting over all or part of a school year (Herrera and Karcher 2013; Laco and Johnson 2017) - is becoming increasingly common. SBM is of particular interest to examining the impact of mentoring on social and economic engagement among young people, as its school-setting means that it is directly relevant to young people's educational context, and studies have highlighted that it can be instrumental to engagement-related areas, such as academic goals and development (Grossman et al. 2012; Laco and Johnson 2017).

Given its relevance to young people's social and economic engagement - and the importance of youth engagement for long-term outcomes in physical and mental health, social connectedness (Reeve et al. 2016) and adult employment (Coles et al. 2010; Shildrick et al. 2012) - this paper focuses on SBM, seeking to understand how it contributes to young people's engagement. While there has been substantial research into SBM, existing research indicates a need to understand more about how SBM operates for young people and how young people themselves perceive it contributes to their lives and engagement. Drawing on an exploratory Australian study, this paper addresses this gap, using young people's qualitative perspectives.

\subsection{Existing research into SBM}

Existing research into SBM highlights clear program goals and outcomes commonly sought from this type of mentoring. SBM programs typically seek to support young people at the early stages of disengagement, often targeted to those seen as at-risk of disengaging from school. SBM programs usually seek to address a combination of education and wellbeing outcomes, which, if left unaddressed, might contribute to pathways towards disengagement. Key examples of educational outcomes sought include improved school attendance (Coller and Kuo 2014), retention (Fredericks et al. 2017) and academic performance (De Anda 2001; Raposa, Rhodes, and Herrera 2016). Key wellbeing outcomes include areas such as improving young people's self-esteem, confidence and feelings of connectedness (Karcher 2005; Portwood et al. 2005).

The extent to which SBM contributes to positive outcomes for young people is widely debated. Some studies have found evidence of SBM contributing to improved grades (De Anda 2001; Fruiht and Wray-Lake 2013), educational confidence (Rhodes 2008; Herrera et al. 2011; Wesely et al. 2017), classroom behavior and attendance (Coller and Kuo 2014; Erdem et al. 2016), as well as improvements in self-esteem, social skills, empathy, cooperation and connectedness (Karcher, Davis, and Powell 2002, Karcher 2005, 2008). However, other studies have highlighted that SBM programs may have little impact on these areas (Slicker and Palmer 1993; Lee and Cramond 1999), may have an impact that is not sustained past the end of the program (Herrera et al. 2011; Augustine 2014) or, 
in certain circumstances (such as where a young person's mentor changes during the program), may even have a negative impact on young people (Grossman et al. 2012).

These mixed findings have led to considerable debate about the utility and benefit of SBM, and about the extent to which, and circumstances in which, it can help young people. Key concerns about SBM generally center on the short-term nature of most programs. SBM is typically delivered over the course of approximately 5 months to coincide with the pattern of the school year, while research on youth mentoring generally recommends that, to achieve sustainable outcomes, programs need to run for no less than 12 months (Grossman et al. 2012). In this context, researchers have questioned whether SBM terminates before it reaches the outcomes it seeks, and whether the results of SBM are dominated by short-term effects, rather than longer-term impact (Herrera et al. 2011). There have also been questions about the order in which outcomes are achieved, and implications for what can be achieved during the short duration of a SBM program. Converse and Lignugaris/Kraft (2008), for example, has questioned whether mentoring may initially impact young people's attitudes about school and school personnel, before it impacts their self-esteem or selfconcept; while Karcher, Davis, and Powell (2002) have questioned the causal relationship between behavioral/academic improvement and psychological/attitudinal improvement, hypothesizing that these two areas are inter-dependent and that it may not be possible to identify if one comes before the other.

Alongside concern about the short-term nature of its programs, there have also been countersuggestions that SBM simply operates through different pathways to other mentoring programs. Herrera et al. $(2011,347)$ have suggested that 'the school-based nature of SBM interactions may prime the mentoring relationship to operate through different pathways that may help [young people] in a range of academic, social and behavioral areas - particularly those evident in the school environment'. They suggest, for example, that SBM may have an impact through improving young people's relationships with teachers or by fostering young people to have a more positive experience of and outlook on school, both of which may, in turn, foster more traditional outcomes sought from mentoring, such as improved school attendance or academic performance. This suggests that beyond simply quantifying outcomes at the end of a given period of mentoring delivery, there is more to understand about the types and sequence of outcomes SBM seeks to address.

These questions about program duration and the type, order or sequence in which outcomes are achieved reflect the complexity of understanding the impact of SBM programs on young people, and the complexity of understanding influences upon young people's engagement more generally. Increasingly, research is highlighting that young people's experiences of engagement in education and employment now follow complex pathways. Due to increasing instability in education and employment contexts, it cannot be assumed that there is only one linear route to desired engagement outcomes, as such a trajectory has become less relevant and/or possible for many young people; rather, for many contemporary young people, there are a multiplicity of possible ways they may experience changes and progression in their engagement over time (Wyn and Woodman 2006; Worth 2009; Woodman and Wyn 2013; FYA 2018). Overall, there is a need for a more thorough understanding of the whole range of possible pathways through which outcomes from SBM may be achieved in young people's lives. This includes a role for qualitative research to draw on the accounts of young people themselves to show more about how mentoring outcomes develop in their lives and how and through what range of pathways mentors may make an impact upon their engagement (Denzin and Lincoln 2005). Consistent with participatory frameworks that aim to prioritize the voices of young people themselves in the construction of authentic knowledge about their lives (ARACY 2009), such research can provide greater insight into what outcomes are 
experienced by young people taking part in SBM and in what ways. It also has implications for how mentoring outcomes can or should be conceptualized and measured.

Drawing on an Australian study of the qualitative perspectives of 15 young people engaged in SBM, this exploratory paper uses young people's lived experiences to develop insights into the outcome pathways of SBM. The paper finds that in some cases, mentors take a direct approach to addressing key outcome areas in social and economic engagement, whereas in others, a more holistic approach is taken.

\section{Methods}

The analysis in this paper is drawn from a qualitative exploratory study of a 6-month Australian SBM program. The focus was understanding the impact of SBM on young people's educational engagement and wellbeing and on developing supportive communities for young people.

\subsection{About the mentoring program}

Conducted over two school terms, the program was delivered via a not-for-profit organization to young people aged 13-15 who were assessed by their school to be at-risk of disengaging from education. The not-for-profit organization enlists and trains mentors, who they then connect to high school students through a structured program, brokered through each school. The program offers 20 one-hour weekly meetings with an assigned mentor. Mentors are volunteers from a range of backgrounds including general volunteers, allied health and social work students and mentors participating through corporate social responsibility programs at their workplace. They do not usually have a pre-existing personal connection to the school or student. All mentors complete an accredited vocational education course in mentoring (12 hours of training), and receive ongoing supervision from the program coordinator. The goals of the program are to effect positive change in several areas related to engagement (participation in education/employment, goal-setting and academic achievement) and wellbeing (relationships, resilience, coping, confidence and selfesteem).

\subsection{Data collection}

The research took place in five public, co-educational metropolitan high schools (grades 7-12) in a large Australian city. Schools were selected to ensure coverage of a range of socio-economic characteristics, to in turn ensure that the research covered a variety of contexts for mentoring. Each school participated after the principal was approached via the not-for-profit mentoring organization. As a small exploratory study, the research targeted and recruited 15 young person-mentor pairs, with more participating from some schools than others depending on the number who consented. This paper is however based on the accounts of young people only, not mentors. Their demographic characteristics are shown in Table 1.

The research followed ethical protocols for conducting research with children and young people, as well as potentially vulnerable groups, with approval through a university human research ethics committee and the relevant government education department. Participants were recompensed for their time with a gift voucher. The young people's emotional support during the study was ensured through welfare contacts at their school and through the mentoring program coordinator in each school.

Young people participated in one semi-structured interview each, within a month of completing the SBM program. Young people were asked about their education, employment (i.e. casual work 
outside school hours), future aspirations (i.e. aspirations for employment in adulthood), interests and extra-curricular activities, and their relationships with family, friends and trusted adults. They were first asked what was currently happening for them in each of these areas, and then asked to elaborate on whether and how the mentoring program had assisted them in that area and what else had helped them with that part of their life. This structure was designed to establish whether and then how mentoring may have helped young people in each area, without assuming it had necessarily done so.

Table 1. Demographic characteristics of young people

\begin{tabular}{|c|c|c|}
\hline & N & $\%$ \\
\hline Gender & & \\
\hline Female & 7 & 46.7 \\
\hline Male & 8 & 53.3 \\
\hline Age & 1 & 6.7 \\
\hline 13 & 11 & 73.3 \\
\hline 14 & 3 & 20.0 \\
\hline 15 & & \\
\hline Cultural background & 6 & 40.0 \\
\hline Culturally diverse & 9 & 60.0 \\
\hline Anglo & & \\
\hline
\end{tabular}

\subsection{Data analysis}

With consent, interviews were audio-recorded, then transcribed verbatim and analyzed using NVivo 11. Thematic analysis was conducted through immersion in the data, by repeated close reading of the interview transcripts, and then a thematic categorisation/coding process, which included initial basic organizing of the data and then a more refined search for themes. Data were first thematically coded to pre-set nodes grouped under economic engagement (how engaged young people were with education and work, and whether they had education or work-related aspirations); wellbeing (confidence, everyday coping/communication, interests/activities, mental health, talking/listening); and supportive communities (relationships with family, friends, peers, trusted adults and teachers, community engagement). Data was double-coded where it related to more than one node. At the end of this process, some nodes had more data than others, for example, the volume of data in the 'engagement' and 'wellbeing' nodes was larger than that in the 'supportive communities' nodes. Following the initial coding, data within specific nodes was re-analyzed to draw out more refined themes in young people's accounts. The re-analysis categorized data according to young people's own perspectives, and resulted in the themes detailed in the findings section of this paper. This paper primarily reports on the re-analysis of the data coded under the initial category of 'education' - as this most directly relates to young people's current situation regarding educational dis/engagement - although, in some cases, data that was double-coded at various 'wellbeing' nodes are included, to demonstrate the outcome pathways between education and wellbeing.

\section{Findings}

Young people spoke not only about what change mentors had made in their lives, but also how they had done so - the actions mentors had taken and the areas they addressed. Their accounts highlight that in some cases, pathways to influencing young people are through directly addressing areas related to education and engagement, such as academic performance and achievement, whereas in other cases, pathways were through a more holistic approach that addressed key areas of wellbeing that might otherwise present a barrier to young people in effectively engaging in education. Both 
types of outcome pathways are explained in more detail below, using young people's perspectives, and are depicted in Figure 1. Young people usually, although not exclusively, reported mentors following one or the other of the types of pathways, not both.

\section{Figure 1. Direct and holistic pathways to youth mentoring outcome}

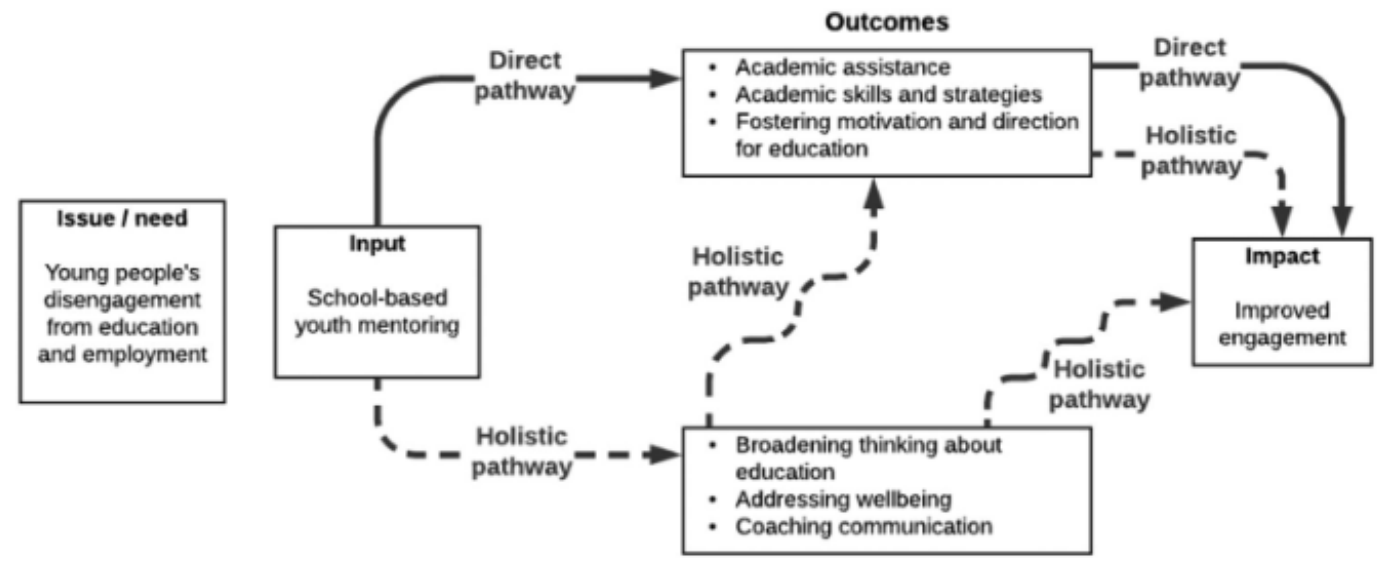

\subsection{Direct engagement pathways}

Several young people spoke about how their mentor had directly addressed areas related to their educational engagement, primarily academic performance and achievement. Their accounts revealed ways in which young people and mentors had participated together in actions and discussions that were directly intended to build their academic performance and achievement, some with shorter- and some with longer-term implications. These are referred to as 'direct engagement pathways' here, as the interventions and actions taken address improved educational engagement in a 'direct' or straight-forward manner.

Influencing engagement through direct academic assistance. Some young people noted that mentors provided them with assistance to help them with specific schoolwork. One young person, for example, commented on his mentor providing assistance with a specific assignment:

\footnotetext{
I was talking to [my mentor] about an assignment we had to do for a class and he helped me a lot and we went all right in it. It was a group thing ... the thing was we had to drop an egg from the bridge to the floor, we had to make something to protect it from cracking and because he is an engineer, he was teaching me how to make it perfect and stuff and [we] went all right (male, age 14, Anglo).
}

Others commented on direct assistance with homework and study requirements for particular subjects, sometimes highlighting that mentors made studying fun:

He has been helping me, he asked me 'Do you have any maths homework or something in your bag?' and he does it with me and he helps me learn and stuff (male, age 14, Anglo). 


\begin{abstract}
He would just study with me in science ... it was great. It was really fun ... because he would just do it in fun ways, he wouldn't do it in boring ways ... We'd talk about science or something and then he'll say a joke about it ... And then we'll just have a laugh and then like we'd just like keep talking about the same thing for a while and then 'Okay, that's enough' (male, age 14, non-Anglo).
\end{abstract}

In each of these examples, young people talked about an instance where they participated together with their mentor in a direct, situational interaction intended to build their academic performance and achievement. Each is premised on enacting assistance in the moment, for immediate benefit to a specific educational task: an assignment, piece of homework or set of study requirements. In this respect, it is a way of directly influencing young people's educational engagement, centered on a pathway intended to go directly to a specific short-term outcome.

Influencing engagement through building academic skills and strategies. Young people also described their mentors working with them to build their academic skills and strategies, with the result of improving their performance at school. For example, one young person noted an improvement in her grades in maths and said that she thought this was at least partially due to her mentor explaining better study skills to her:
I came first in my maths class ... because I'm usually really bad at maths and [my mentor] helped me to study and stuff ... she just told me a good way to study. So usually people - if they study all night and then go to bed late, it's still in your short memory, whereas if you study a little bit and have a good sleep, it means that your study will go into your long-term memory, and it helped ... I didn't know that until she told me (female, age 14, Anglo).

Similarly, another young person explained that her mentor had shown her how to better plan and schedule her workload, which she linked to an improvement in her marks on assignments:

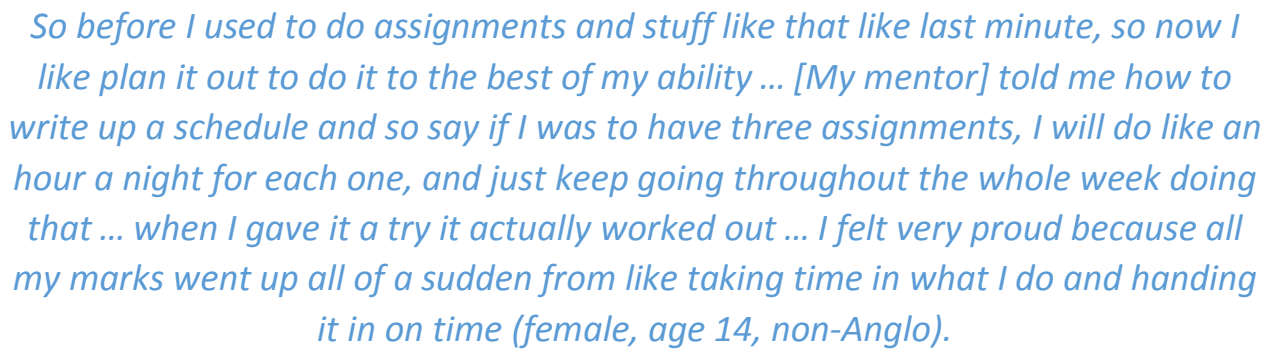

Other young people commented on their mentors assisting with explaining or showing them strategies for how to resist peer pressure in the classroom, listen more effectively in class and improve their time management, organization and focus for their schoolwork.

In each case, young people spoke about how their mentors sought to build their skills and strategies directly for education. These interactions were premised on developing skills that could be used flexibly across a range of instances of engagement - different assignments, classes or exams. In this respect, it is a pathway that directly builds skills for education, prioritizing skills that can be used for 
a range of immediate or short-term outcomes such as performance on the specific maths test or assignments that the young people quoted above had happening at the time, and may also be extended across other school tasks or contexts, both in the present and into the future.

Influencing engagement through fostering motivation and direction for education. Finally, young people described how their mentors had a key role in motivating or encouraging them and in helping them to foster direction in their education. One young person, for example, spoke about the motivating role of conversations with her mentor as she worked to improve her grades:

I've actually been able to talk to her about how I got good grades and she's always been happy for me with that ... she's been happy that I got the grade that I wanted to get, working hard ... We were once sitting down and talking and I was telling her about how I used to get modified [remedial] sheets [but not anymore], and she said ... I've got to keep putting the work in and the effort and it'll pay off and stuff (female, age 14, non-Anglo).

Others commented on their mentor assisting them with goal-setting, which could also be motivating in identifying the attitude or work ethic involved in meeting goals. One young person commented:

\author{
I noticed there's a lot about goal-setting [in mentoring] and what you want to \\ head or achieve for and school came into that quite a bit ... saying I want to \\ improve in this area of maybe maths, or I would like to achieve something along a \\ subject ... [my mentor helped me set] a good work ethic or better work ethic or \\ more attitude towards it, I guess. It helped to reflect on what you want to do, \\ how you could make yourself better in that way (male, age 14, Anglo).
}

In each case, the interaction between the young person and mentor was an exchange directly centered on cultivating motivation and goals that young people will benefit from as they seek to progress in their education. While goal-setting may be considered an outcome in itself, it is also an interaction premised on fostering the encouragement that young people may need to progress educationally, that they may or may not receive elsewhere. In this respect, it is again a pathway that directly assists with education - one not tied to only one specific outcome, but rather one that may have implications across a range of immediate or short-term outcomes and which is also oriented towards impact into the future.

A common thread across each of these three pathways was that the primary object and strategy in each directly addressed young people's education. While the pathways have different orientations in what they seek to influence and how (e.g. whether they seek to influence immediate, shorter- or longer-term/future outcomes), each directly addresses academic performance and achievement head on. Each seeks to influence young people by going to the heart of their education and prioritizing educational performance and achievement as the primary topic of conversation and work within the mentoring relationship. This direct approach was not, however, the only type of pathway undertaken - as evident in the next set of findings from young people.

\title{
3.2. Holistic engagement pathways
}


Young people also spoke about how mentors had addressed areas of their lives such as their broader thinking about the value of education, their wellbeing and their communication skills, which in turn had an impact on their engagement in their education (as well as other areas of their lives). In this respect, they showed how mentors could follow more holistic pathways, intended to address areas which could otherwise present a barrier to their engagement. These are referred to as 'holistic engagement pathways', as the interventions and actions taken do not directly address the central outcome of improved educational engagement, but do so via other areas, which in turn impact engagement. $^{1}$

Influencing engagement through changing broader thinking about the value of education. Some young people noted that rather than directly trying to influence their academic performance or achievement, mentors instead sought to influence their broader thinking about the value of education and engagement. For example, one young person, who had significant stressors in her home and family life that had influenced her to disengage from school, said:

\begin{abstract}
I was slacking off badly, and I started not going to most of my classes, or if I was in class, l'd just be on my phone, or just doing random stuff on my laptop. Not really listening, not caring. I went to a really bad state ... so [my mentor] helped me realise that everything will be eventually over. Because [my mentor] didn't say to me, 'Everything will be alright', because I hate it when people say it to me ... so [instead] she said stuff like, 'Everything's not going to be bad for so long. It might not be now, it might not be next year, it might not be four years; but you can do this, and everything is not as bad as it seems'. Which made me click on ... [My mentor] made me realise that you can't let things affect you ... you can't let them affect your school work. Your school work is yours, no one else's ... it's not what she said, it's what she helped me realise (female, age 13, Anglo).
\end{abstract}

Another young person explained how his mentor had 'unlocked the padlock, and opened up [his] mind', thereby helping him to find ways to enjoy and see a purpose in his education:

I've never enjoyed learning ... [My mentor] said, 'You've got to find a way to love it, because there's no way you're really going to get out of it' ... I disliked English a lot more, and then I spoke to [my mentor] about it, and after half an hour of speaking to him about it, I saw that there is actually [a] positive, and I may as well learn it, and [it] might be useful in trivia ... maybe l'll win a \$100 gift card on a trivia night ... I was locked in the perspective of, 'It sucks'. He got me out of that perspective ... I think just talking to me, he kind of showed me, in his own way, how English could be a positive thing ... it kind of just changed my mind, and I said, 'Oh, wait, there is actually a different side to this'. And I tried it out, and it worked ... It made school better; it hasn't made it the best thing in my life, but it definitely made it more enjoyable than it was before (male, age 14, Anglo).

In each case, the young people suggested that before they can improve directly in engagement, a first step is to more holistically address the way they think about education and its value and role in their lives, in order to influence the extent to which they want to be at school. The interaction between the young person and mentor was centered on discussing and changing the young person's 
views on education, to in turn impact their level of engagement. In this respect, while it may have an impact either in the immediate or longer-term, overall, it is a holistic pathway to improving engagement, one premised on changing young people's overall concept of why engagement is important and what it can mean to them, rather than directly addressing any one specific engagement outcome.

Influencing engagement through addressing wellbeing. Other young people noted that their mentors had had a key role in addressing issues affecting their wellbeing, which in turn influenced their education. ${ }^{2}$ Often this was where their mentor helped them learn ways to deal with stress, anxiety and other mental health issues, which made it hard for them to engage effectively in their education.

One young person, for example, spoke about how his mentor had helped him understand how to manage anger in the classroom, which enabled him to go from being sent out of class almost every day to not being sent out very often at all:

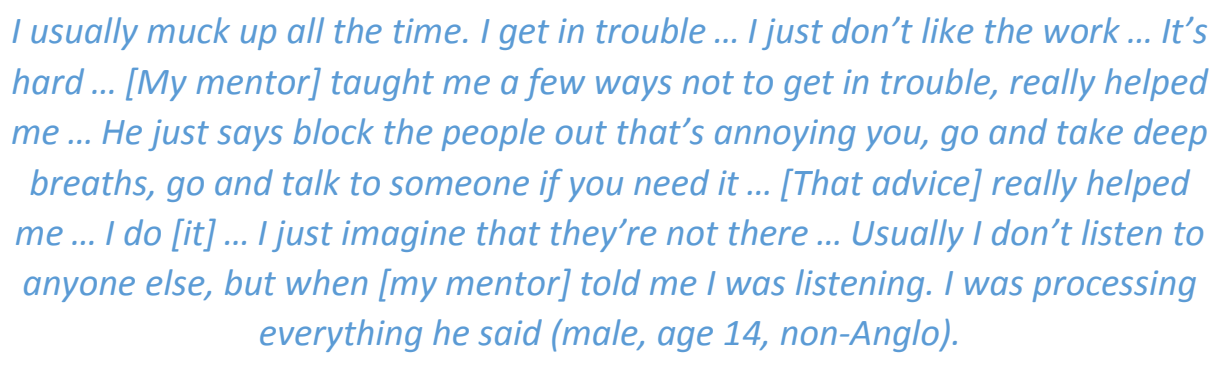

Other young people mentioned their mentor talking with them about stress or anxiety they experienced in the classroom or about their schoolwork, including offering practical ways to address this, such as breathing exercises.

Like the young people who suggested that changing their broader thinking about the value of education was an important but indirect first step in influencing their educational engagement, the young people here suggested that addressing wellbeing issues is similarly an important start to influencing their engagement. Each interaction between the young person and mentor was about discussing ways to holistically improve their wellbeing, with one, but perhaps not the only, purpose being to help them engage with school. Again, while it may have an impact either in the immediate or longer-term, overall, it is a holistic strategy that goes beyond only addressing one specific engagement outcome.

Influencing engagement through coaching communication with teachers. Finally, other young people noted that their mentor had coached them in their communication with teachers, which had facilitated them in resolving or otherwise dealing with conflicts which could affect their educational engagement.

One young person explained how her mentor had helped her understand more about the subtleties of communication across relationships with power differentials - such as student-teacher relationships - which helped her understand more about and know how to manage relationships with her teachers: 


\begin{abstract}
When I tell [my mentor] a problem she gives me tips on how to solve them and they're usually really good ones, most of the time I use them ... So I had a fight with one of my teachers ... and [my mentor] printed out some papers on if two people want to win an argument then if you want to solve it then one person has to give in and so the other person can win, and usually it's solved like that ... [I thought] 'Well, it's something new', so I thought I might try it, and it did work ... I apologised to [the teacher] and told him I was really sorry, and he said 'That's okay' and he just forgave me (female, age 14, Anglo).
\end{abstract}

Another young person commented on his mentor helping him to think of strategies that he could use, beyond conflict, to deal with a teacher who he felt did not treat him fairly:

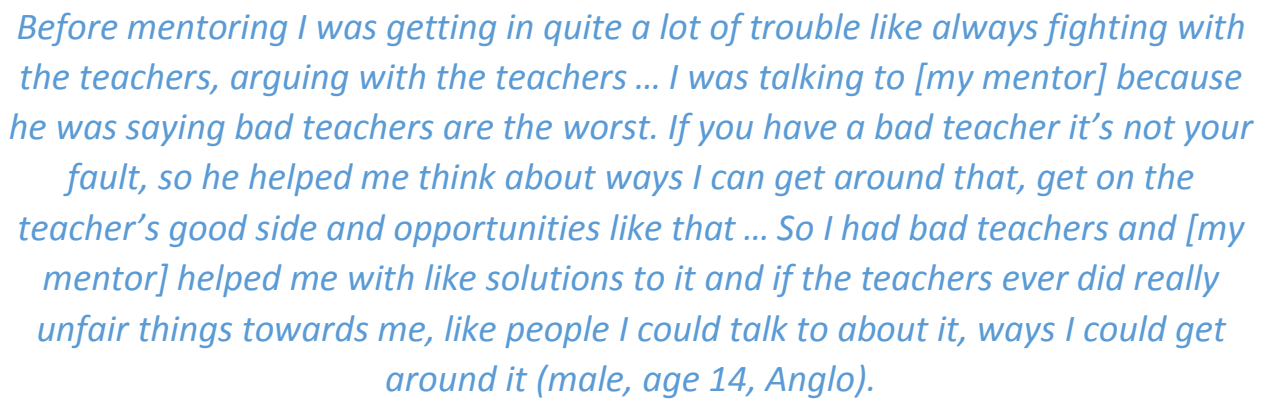

In each example, the mentors were not addressing specific issues such as school attendance or academic performance, but rather helped to develop a pathway to engagement based on influencing more holistic experiences of being at school, which may in turn impact on educational engagement by removing barriers to young people focusing on their education. By coaching young people in their communication with teachers, the mentors provided a form of personal development that is holistic, helping young people to come to more informed and effective communication skills, which may assist in their educational engagement, but also other areas of their lives.

Each of these three pathways highlight holistic ways of influencing young people's engagement. In none do mentors directly address key educational outcomes often seen as the preferred direct outcome areas of SBM, such as school attendance, retention or academic performance or achievement. Rather, mentors help young people with a range of skills that may impact on their engagement with education over time. By addressing these more holistic areas, pathways may be developed that can help with young people's immediate or short-term engagement, but which may also have a longer-term impact, through changing the personal resources with which they approach their education and engagement (as well as other areas of their lives) over time.

\title{
4. Discussion and conclusions
}

This paper sought to provide new exploratory insights into the pathways through which SBM contributes to improved educational engagement outcomes in young people's lives. It used qualitative accounts to show how young people perceive the role of SBM. The paper sits against existing literature in which the complexity of understanding the impact of SBM programs has been demonstrated (Karcher, Davis, and Powell 2002; Converse and Lignugaris/Kraft 2009; Herrera et al. 2011), particularly as linear pathways towards improved engagement outcomes have become less 
relevant for many young people (Wyn and Woodman 2006; Worth 2009; Woodman and Wyn 2013). The paper therefore sought to articulate more about the range of possible ways that SBM may make an impact in young people's lives.

The findings highlight two types of outcome pathways through which mentoring may influence young people's educational engagement. Direct pathways go to the heart of young people's engagement, by prioritizing educational performance and achievement as the primary topics of conversation and work within the mentoring relationship. These pathways involve mentors providing young people with academic assistance, building young people's academic skills and strategies, and fostering young people's motivation and direction for education. However, holistic pathways are also evident. Consistent with Herrera et al.'s (2011) suggestion that SBM can operate through improving young people's outlook on school and their relationships with teachers, these pathways involve mentors seeking to change young people's broader thinking about the value of education, address issues affecting young people's wellbeing and coach young people in more effective communication with teachers, to, in turn, improve their engagement outcomes. In this respect, the direct pathways may be considered to reflect an instrumental approach to mentoring, focused on building specific skills and goals, while the holistic pathways reflect a developmental approach, based on socio-emotional development (Raposa, Rhodes, and Herrera 2016). Young people usually, although not exclusively, reported mentors either following a direct or holistic pathway with them, but not both. As such, the direct and holistic pathways take very different forms, and, in many respects, represent very different routes to making a difference to young people's engagement. Yet the accounts of the young people in this research highlight that both types of pathways are valued by young people and are seen to make a difference in their lives.

These findings make an important contribution to understanding the variety of pathways through which SBM operates and to understanding how positive change can be influenced in young people's lives and engagement. The two types of pathways help to fill out an understanding of the complexity of influencing young people's educational engagement. They highlight that while sometimes directly improving engagement areas such as academic performance and achievement can be the direct object of SBM, at other times it may not be possible to go directly to these practical performanceoriented outcomes. Instead, there must be a prior pathway or first step through other more holistic areas, for example, addressing how young people value education, their wellbeing or their communication skills. The implication is that there is not always a linear or direct route to improving young people's educational engagement, but rather the pathway to doing so may have diversions, 'twists' or 'turns' through a range of other areas, which may seem unrelated, but which are actually related to how young people narrate their own experience of changed educational engagement. This suggests the need to see young people's educational engagement and the role of SBM holistically, and to account for progress towards engagement wherever and however it occurs, not only when the final intended outcome of reaching a defined marker of improved engagement is achieved. This is important as young people themselves highlighted the fundamental importance that changed thinking about the value of education, strategies to help with wellbeing or coaching in communication skills can play in progressing or improving in their engagement. As such, these elements should not be ignored.

Despite these findings, it is also however important to appreciate that young people's perspectives are formed in a context where society gives messages about what 'improvement' in engagement should be like. A critique of the findings here could be that mentoring appears to promote 'fixing' individuals, rather than addressing the circumstances and structures in which they are set. However, the very nature of mentoring means that 'improved engagement' is about improving individual personal development, not challenging or changing societal structures that frame young people who 
do not engage as problematic. Accordingly, there were no young people in the study who challenged the notion that they needed help to engage, although this is perhaps to be expected from those who had agreed to participate in SBM.

Seeing the different types of pathways to influencing young people's educational engagement has implications for thinking about how the success of SBM programs is understood. Research has sometimes found that SBM may have little, unsustained or no impact on young people's engagement outcomes (Slicker and Palmer 1993; Lee and Cramond 1999; Herrera et al. 2011; Augustine 2014). These studies may however only measure the linear impact of SBM against a defined set of markers of final or end-outcomes, such as improved school attendance, retention, academic performance/achievement, behavior or educational confidence. Understanding that progressing towards improved engagement is an ongoing, continuous and non-linear experience for contemporary young people helps to see that a range of holistic factors may play a role along the way, and that holistic changes that contribute to incremental steps on a pathway to improved engagement still - from the perspective of young people - represent a beneficial outcome in their lives. This means that just because an intervention such as SBM may not always achieve all of its intended impact in the time available does not mean that it is not valuable to young people as they improve their engagement; rather, it may be helping young people to build holistically towards the personal resources they need to improve their own engagement over time, through a less-linear route.

The policy implication is that SBM can be a flexible intervention that can cater to contemporary young people who are not navigating straight-forward routes to engagement outcomes. Through its capacity to follow different types of pathways, SBM represents a flexible tool for policy and practice in reaching goals for improved educational engagement in a context of complexity in influencing young people's engagement trajectories. Different young people may need different resources and impacts from mentoring to assist their engagement, and through its direct and holistic pathways, SBM may be able to offer the variety of what different young people need. This positions SBM as a flexible and holistic resource that contemporary policy may draw on to influence and impact young people's engagement.

A further policy implication is that there should be greater consideration of how the holistic pathways are reflected in how the success of SBM is measured. There is a role for measurement of outcomes in SBM that takes more account of incremental changes, and that reflects the holistic ways that some young people say that SBM makes change in their lives. This may be achieved through following recent outcomes measurement advice about defining short-, medium- and longterm outcomes when determining what will be measured (Social Ventures Australia n.d.), as well as focusing not only on the primary outcome or impact to be achieved, but also the secondary and intermediate outcomes through which progress towards the final impact may occur (Harries, Hodgson, and Moble 2014; Office of Social Impact Investment 2016). Each of these strategies may enable appreciation of holistic pathways to outcomes in youth mentoring. Overall, the holistic pathways need to be built into the outcomes measurement frameworks through which SBM is commissioned and its success measured, as without the holistic pathways forming a component of outcomes measurement in SBM, understanding of the outcomes from SBM may only ever be partial.

While making an important contribution, this paper is not without limitations. The sample size is small and drawn from only one SBM program - a larger sample spread across a variety of programs would further confirm the findings and show more about how SBM contributes to young people's lives in different settings, school contexts and program structures. It would also allow better understanding of the extent to which mentoring is beneficial for all or only some young people. Collecting the perspectives of other people involved in SBM programs, such as school or mentoring 
administrators, may also assist this goal. Further, the paper is based on cross-sectional not longitudinal data, meaning that there was no opportunity to see how outcomes eventuate over time. A future longitudinal study would add further insight. Future research could also examine which young people benefit most from the direct and holistic pathways, and whether young people's socio-demographic characteristics are related to which type of pathway may be most relevant to them.

Overall, this paper has shown more about how SBM contributes to improvements in young people's educational engagement through different pathways. Understanding that there are both direct and holistic pathways through which SBM can influence young people's engagement helps to show more about young people's experience of this type of mentoring, and also helps to broaden understandings of what success in SBM looks like. Both are important contributions as SBM continues to be used to help young people improve in their educational engagement and to avoid the risks that disengagement presents over the life course.

\section{Notes}

${ }^{1}$ If progress towards broader thinking or changed wellbeing or communication was being measured as the central outcome in itself, rather than progress towards improved engagement, then these would be direct, not holistic, pathways. The framing of the pathway depends on the overall impact in question.

${ }^{2}$ Consistent with the focus of this paper on economic engagement, this section only covers wellbeing data that intersected with participants' discussions of their education. While participants spoke about fuller range of aspects of wellbeing including mental health and self-concept, where they mentioned an impact of mentoring on their wellbeing without drawing a link to education or economic engagement, this is considered outside the scope of the paper.

\section{References}

ARACY. 2009. Involving Children and Young People in Research [Electronic Resource]: A Compendium of Papers and Reflections from a Think Tank Co-hosted by the Australian Research Alliance for Children and Youth and the NSW Commission for Children and Young People on 11 November 2008. ACT and Sydney.

Augustine, K. A. 2014. "Teacher Mentors: Lived Experiences Mentoring At-Risk Middle School Students." Doctor of Education. Drake University.

Coles, Bob, Christine Godfrey, Antonia Keung, Steven Parrott, and Jonathan Bradshaw. 2010. Estimating the Life-Time Cost of NEET: 16-18 Year Olds not in Education, Employment or Training. York: University of York.

Coller, R. J., and A. A. Kuo. 2014. "Youth Development through Mentorship: A Los Angeles Schoolbased Mentorship Program among Latino Children." Journal of Community Health 39 (2): 316-321. doi: 10.1007/s10900-013-9762-1

Converse, Noelle, and Benjamin Lignugaris/Kraft. 2009. "Evaluation of a School-Based Mentoring Program for at-Risk Middle School Youth." Remedial and Special Education 30 (1): 33-46. doi: 10.1177/0741932507314023

De Anda, Diane. 2001. "A Qualitative Evaluation of a Mentor Program for at-Risk Youth: The Participants' Perspective." Child and Adolescent Social Work Journal 18 (2): 97-117. doi: 10.1023/A:1007646711937 
Denzin, N., and Y. S. Lincoln. 2005. "The Discipline and Practice of Qualitative Research." In The SAGE Handbook of Qualitative Research, edited by N. Denzin and Y. S. Lincoln, 1-20. Thousand Oaks: SAGE.

Erdem, Gizem, David L. DuBois, Simon Larose, David De Wit, and Ellen L Lipman. 2016. “Mentoring Relationships, Positive Development, Youth Emotional and Behavioral Problems: Investigation of a Mediational Model." Journal of Community Psychology 44 (4): 464-483. doi: 10.1002/jcop.21782

Fredericks, Brownyn, Susan Kinnear, Carolyn Daniels, and Marina Mikecz. 2017. "The Positive Impacts of AIME on Indigenous Education Outcomes: A Case Study of Indigenous Student Retention and Transition in Central Queensland".

Fruiht, Veronica M, and Laura Wray-Lake. 2013. "The Role of Mentor Type and Timing in Predicting Educational Attainment." Journal of Youth and Adolescence 42 (9): 1459-1472. doi: 10.1007/s10964-012-9817-0

FYA. 2016. Renewing Australia's Promise: Report Card 2016. Melbourne: Foundation for Young Australians. Online.

FYA. 2018. "The New Work Reality." In New Work Order Report Series. Melbourne: Foundation for Young Australians.

García-Carrión, Rocío, Fidel Molina-Luque, and Silvia Molina Roldán. 2018. "How Do Vulnerable Youth Complete Secondary Education? The key Role of Families and the Community." Journal of Youth Studies 21 (5): 701-716. doi: 10.1080/13676261.2017.1406660

Grossman, Jean B., Christian S. Chan, Sarah E. O. Schwartz, and Jean E. Rhodes. 2012. "The Test of Time in School-Based Mentoring: The Role of Relationship Duration and Re-matching on Academic Outcomes." American Journal of Community Psychology 49 (1-2): 43-54. doi: 10.1007/s10464-011-9435-0

Harries, E., L. Hodgson, and J. Moble. 2014. Creating Your Theory of Change: NPC's Practical Guide. London: NPC.

Henry, N. 2006. Mentoring Myths and Tips. Washington, DC: The Resource Center. http://nationalserviceresources.org/mentoring-myths.

Herrera, Carla, Jean Baldwin Grossman, Tina J. Kauh, and Jennifer McMaken. 2011. "Mentoring in Schools: An Impact Study of Big Brothers Big Sisters School-Based Mentoring." Child Development 82 (1): 346-361. doi: 10.1111/j.1467-8624.2010.01559.x

Herrera, C., and M. J. Karcher. 2013. "School-based Mentoring." In Handbook of Youth Mentoring, edited by D. L. DuBois and M. J. Karcher, 203-220. Thousand Oaks, CA: SAGE.

Jacob, Marita. 2008. "Unemployment Benefits and Parental Resources: What Helps the Young Unemployed with Labour Market Integration?" Journal of Youth Studies 11 (2): 147-163. doi: 10.1080/13676260701863413

Karcher, Michael J. 2005. "The Effects of Developmental Mentoring and High School Mentors' Attendance on Their Younger Mentees' Self-Esteem, Social Skills, and Connectedness." Psychology in the Schools 42 (1): 65-77. doi: 10.1002/pits.20025

Karcher, Michael J. 2008. "The Study of Mentoring in the Learning Environment (SMILE): A Randomized Evaluation of the Effectiveness of School-Based Mentoring." Prevention Science 9 (2): 99-113. doi: 10.1007/s11121-008-0083-z 
Karcher, Michael J., Claytie Davis III, and Brad Powell. 2002. "The Effects of Developmental Mentoring on Connectedness and Academic Achievement." School Community Journal 12 (2): 35.

Laco, Dávid, and Wendy Johnson. 2017. "I Expect it to Be Great ... But Will it Be?' An Investigation of Outcomes, Processes, and Mediators of a School-based Mentoring Program." Youth \& Society $0044118 \times 17711615$.

Lee, Jongyeun, and Bonnie Cramond. 1999. "The Positive Effects of Mentoring Economically Disadvantaged Students." Professional School Counseling 2 (3): 172.

Office of Social Impact Investment. 2016. Technical Guide: Outcomes Measurement for Social Impact Investment Proposals to the NSW Government. Sydney: NSW Government.

Pawson, R. 2004. Mentoring Relationships: An Explanatory Review (Working Paper 21). Leeds: ESRC UK Centre for Evidence Based Policy and Practice.

Portwood, Sharon G., Penny M. Ayers, Kelly E. Kinnison, Robert G. Waris, and Daniel L. Wise. 2005. "YouthFriends: Outcomes from a School-Based Mentoring Program." The Journal of Primary Prevention 26 (2): 129-188. doi: 10.1007/s10935-005-1975-3

Powell, A. 2017. NEET: Young People Not in Education, Employment or Training - Briefing Paper. London: House of Commons Library

Raposa, Elizabeth B., Jean E. Rhodes, and Carla Herrera. 2016. "The Impact of Youth Risk on Mentoring Relationship Quality: Do Mentor Characteristics Matter?" American Journal of Community Psychology 57 (3-4): 320-329. doi: 10.1002/ajcp.12057

Reeve, R., A. Marjolin, K. Muir, A. Powell, N. Hannigan, I. Ramia, and L. Etuk, eds. 2016. Australia's Social Pulse. Centre for Social Impact: UNSW Australia, Sydney and UWA, Perth.

Rhodes, Jean E. 1994. "Older and Wiser: Mentoring Relationships in Childhood and Adolescence." The Journal of Primary Prevention 14 (3): 187-196. doi: 10.1007/BF01324592

Rhodes, Jean E. 2008. "Improving Youth Mentoring Interventions Through Research-Based Practice." American Journal of Community Psychology 41 (1-2): 35-42. doi: 10.1007/s10464-007-91539

Rhodes, Jean E., G. Anne Bogat, Jennifer Roffman, Peter Edelman, and Lisa Galasso. 2002. "Youth Mentoring in Perspective: Introduction to the Special Issue." American Journal of Community Psychology 30 (2): 149-155. doi: 10.1023/A:1014676726644

Rhodes, Jean E., Jean B. Grossman, and Jennifer Roffman. 2002. "The Rhetoric and Reality of Youth Mentoring." New Directions for Student Leadership 2002 (93): 9-20.

Shildrick, T. A., Robert MacDonald, Andy Furlong, Johann Rodan, and Robert Crow. 2012. Are 'Cultures of Worklessness' Passed Down the Generations? York: York Joseph Rowntree Foundation.

Slicker, Ellen K, and Douglas J. Palmer. 1993. "Mentoring at-Risk High School Students: Evaluation of a School-Based Program." The School Counselor 40 (5): 327-334.

Social Ventures Australia. n.d. Managing to Outcomes: A Guide to Developing an Outcomes Focus. Sydney: Social Ventures Australia.

Wesely, Jennifer K., Nicholas P. Dzoba, Holly Ventura Miller, and Christine E. Rasche. 2017. "Mentoring at-Risk Youth: An Examination of Strain and Mentor Response Strategies." American Journal of Criminal Justice 42 (1): 198-217. doi: 10.1007/s12103-016-9353-7 
Woodman, D., and J. Wyn. 2013. "Youth Policy and Generations: Why Youth Policy Needs to 'Rethink Youth'." Social Policy and Society 12 (2): 265-275. doi: 10.1017/S1474746412000589

Worth, N. 2009. "Understanding Youth Transition as 'Becoming': Identity, Time and Futurity." Geoforum; Journal of Physical, Human, and Regional Geosciences 40 (6): 1050-1060.

Wyn, J., and D. Woodman. 2006. "Generation, Youth and Social Change in Australia." Journal of Youth Studies 9 (5): 495-514. doi: 10.1080/13676260600805713

\section{Disclosure statement}

No potential conflict of interest was reported by the authors.

\section{Funding}

This work was supported by Macquarie Group Foundation. 